\title{
Formação Docente e a Nova Visão da Avaliação Educacional
}

\author{
ANA MARIA PORTO CASTANHEIRA \\ Professora Titular do Centro de Ciências e Humanidades e Coordenadora da \\ Comissão Própria de Avaliação da Universidade Presbiteriana Mackenzie \\ castanheira@mackenzie.com.br \\ MARY ROSANE CERONI \\ Professora Adjunta e Coordenadora do Curso de Pedagogia do Centro de Ciências e \\ Humanidades da Universidade Presbiteriana Mackenzie \\ maryrosane@mackenzie.com.br
}

\begin{abstract}
Resumo
Baseando-se na importância dos processos de avaliação educacional como caminho fundamental para instituir medidas que melhorem o ensino, e levando em conta a atual relevância da auto-avaliação como processo formativo que conduz ao auto-conhecimento e a uma gestão partilhada com a comunidade acadêmica, desenvolve-se a presente discussão sobre a inserção do novo papel do avaliador, bem como seu mérito como agente de mudanças em razão dos conflitos e da complexidade do processo. O estudo fundamenta-se em uma revisão teórica dos conceitos de avaliação e na reflexão sobre o que é considerado importante na implantação de processos avaliativos, das atividades que contribuem para a formação do docente de ensino superior, assim como a discussão de uma metodologia para a obtenção de dados e sua análise, visando a tomada correta de decisão. A questão central é o que se espera do avaliador sob o ponto de vista das políticas públicas atuais e ate que ponto sua participação poderá impactar na tomada de decisão de cada instituição.

Palavras-chave: avaliação, qualidade, auto-avaliação, formação continuada.
\end{abstract}

\section{Resumen}

Este artículo se basa en la importancia de los procesos de evaluación educativa como camino fundamental para instituir medidas que mejoren la enseñanza y considera la importancia actual de la autoevaluación como un proceso formativo que lleva al autoconocimiento y a una gestión compartida con la comunidad académica. La presente discusión trata de la inserción del nuevo rol del evaluador, así como su importancia como agente de cambios frente a los conflictos y a la complejidad del proceso. El estudio se fundamenta en una revisión teórica de los conceptos de evaluación y en la reflexión de lo que se considera importante en la implantación de procesos de evaluación, de las actividades que contribuyen a la formación del profesor de enseñanza superior, así como la discusión de una metodología para la obtención de datos y su análisis con vistas a la correcta toma de decisiones. La cuestión central es lo que se espera del evaluador desde el punto de vista de las políticas públicas actuales y hasta qué punto su participación podrá tener impacto en la toma de decisiones de cada institución.

Palabras clave: evaluación, calidad, autoevaluación, formación continuada. 


\begin{abstract}
Based on the importance of educational evaluation processes as a fundamental path to create ways to improve the teaching processes, and taking into account the current relevance of self-evaluation as a formation process that leads to self-knowledge and to management shared with the academic community, this discussion will focus on the insertion of the evaluator's new role, as well as on his importance as an agent of change due to the conflicts and the complexity of the process. The study is based on a theoretical review of evaluation concepts and on a reflection about what is considered important in implementing evaluation processes of the activities that contribute to the higher education teacher's enrichment. A methodology to gather data and analyze them aiming at making the most correct decision is also discussed. The central question evolves around what is expected from the evaluator from the point of view of current public policies, and to what extent his participation may have an impact on each institution's decision making process.

Key words: evaluation, quality, self-evaluation, continuing education.
\end{abstract}




\section{INTRODUÇÃO}

Pesquisas realizadas sobre a importância da formação de professores do ensino superior, que destacam transformações relevantes para a atuação desses docentes, evidenciam, ainda, como predominantes, os currículos organizados por justaposição de disciplinas; a figura do professor repassador de conteúdos curriculares fragmentados e desarticulados, nem sempre significativos para os alunos ou mesmo para a realidade presente.

Verifica-se que iniciativas precisam ser tomadas pelas Instituições de Ensino Superior (IES), para que propostas educacionais possam ser desenvolvidas pelo professor de maneira significativa, contribuindo, dessa forma, com a própria universidade. Cabe, hoje, ao docente participar com idéias e ações na transformação da gestão (nas dimensões didáticopedagógicas e comunitárias), da organização curricular, dos projetos educacionais e sociais.

Essas oportunidades implicam valorizar o seu trabalho ao criar condições para análise e compreensão dos contextos organizacional, cultural, histórico-social, inseridos na sociedade e na sua própria atividade docente.

Os contextos acima citados, permeados de conflitos que exigem atitudes éticas e políticas em suas atividades características - o ensino, a pesquisa e a extensão - evidenciam, assim, a indissociabilidade desses três pilares como condição de trabalho para que o processo de ensino e aprendizagem atinja o padrão de excelência, no momento em que a educação superior assume o compromisso com a tão necessária responsabilidade social, por meio de ações comunitárias.

Ao mesmo tempo, deve-se garantir, por meio de processos avaliativos adequados, a qualidade das atividades que compõem a docência, a pesquisa e a extensão, para que possam, efetivamente, contribuir para a formação do educador, apto a enfrentar o cotidiano acadêmico com ações eficientes e eficazes.

A avaliação deve constituir instrumento importante de gestão universitária capaz de indicar caminhos e rever processos. Mais que medir índices de crítica e satisfação, ela está comprometida com a real reflexão acerca de todos os processos e procedimentos. Há necessidade de cuidadosas e profundas análises qualitativas dos resultados obtidos, e todos os agentes envolvidos devem participar e interagir com o processo, a fim de garantir a qualidade. 


\section{UNIVERSIDADE E FORMAÇÃO DE PROFESSORES}

Os pressupostos do ensino e da aprendizagem na universidade, hoje, apresentam os seguintes compromissos: organizar e oferecer um conjunto de conhecimentos, habilidades e atitudes que assegurem, aos estudantes, aprendizagem nos campos científico, pessoal e profissional; incentivar o comprometimento com as questões culturais e sociais, de forma crítica e autônoma, e com a produção de novos conhecimentos; considerar o processo de ensinar e aprender como atividade integrada à investigação; desenvolver a capacidade de investigação, ação-reflexãoação; criar e recriar situações de aprendizagem.

Os pressupostos de estratégias de sala de aula estão relacionados à ensinagem (termo usado por Anastasiou, 2003), que significa uma situação de ensino da qual necessariamente decorra a aprendizagem, que estabelece parceria entre professor e aluno -, condição fundamental para o enfrentamento do conhecimento, necessário à formação do graduando; a aula, entendida como momento e espaço privilegiado de encontro e de ações, não deve ser dada pelo professor, mas construída na ação conjunta entre ele e o aluno.

Masetto (1998, 2003), entre outras ponderações relativas às mudanças no ensino superior, alerta sobre a superação da formação voltada apenas para o aspecto cognitivo, e pontua que no processo de ensino é indispensável a preocupação com o desenvolvimento da aprendizagem dos alunos:

O que se busca é que o aluno em seus cursos superiores esteja desenvolvendo competências e habilidades que se esperam de um profissional capaz e de um cidadão responsável pelo desenvolvimento de sua comunidade. Isso fez com que os cronogramas curriculares se abrissem para atividades práticas integrando-se com teorias estudadas e a discussão de valores éticos, sociais, políticos, econômicos, por ocasião do estudo de problemas técnicos, integrando-se à análise teórico-técnica de determinada situação com os valores humanos $e$ ambientais presentes $e$ decorrentes da solução técnica apresentada. (p. 23)

Assim, o estudante de hoje nota rapidamente quando está recebendo assuntos copiados de material ultrapassado, informações reproduzidas que não vão agregar nenhum valor à sua educação profissional. Percebe-se a necessidade de investir na valorização da capacidade de decisão do docente nessa prática social tão complexa por meio de discussão de temas relativos ao cotidiano universitário, como projeto pedagógico, ação coletiva interdisciplinar, cultura, identidade 
profissional, entre outros contextos articulados com os institucionais e comunitários.

\section{AVALIAÇÃO - BREVE REVISÃO DE CONCEITOS}

Para Sobrinho (2006), o conceito de avaliação é globalizado:

A Avaliação não é um processo autolimitado, que basta em si mesmo. Visando tornar mais visível e compreensível o cotidiano de uma instituição, a avaliação ultrapassa os âmbitos mais restritos do objeto a avaliar e lança seus efeitos sobre o sistema de educação superior e suas funções relativamente à construção da sociedade. Ela ilumina e instrumentaliza as reformas educacionais, desde a mudança nos currículos, maneiras de organização de cursos e formas gerenciais, até novas estruturas do sistema. Em outras palavras, a avaliação está no centro do processo de reformas, no foco de competições institucionais, e só ela garante a sobrevivência do ensino de excelência buscado pelas sociedades contemporâneas. (p. 95)

Na verdade, o ato de avaliar está incorporado de forma intuitiva e espontânea no cotidiano, principalmente escolar. São inúmeros os conceitos formais de avaliação; cada um deles mostra um enfoque diferente e deixa claro sua complexidade. A avaliação da aprendizagem é a mais estudada; no entanto, cada vez mais existe grande preocupação em aplicar esses conceitos de forma regular e sistêmica para contribuir com as mudanças da sociedade.

A concepção de avaliação está ligada ao ato de escolher, de optar. No mundo contemporâneo, a avaliação é usada como instrumento para selecionar, aprovar ou capacitar trabalhadores, contribuindo para uma melhor gestão. Todavia, na educação, sempre teve seu lugar privilegiado como prática pedagógica, mas também é utilizada na regulação, seleção e hierarquização, seja na sala de aula seja em domínios mais amplos.

Stuffebeam e Shinkfield (1987) destacam cinco períodos nos quais a avaliação foi entendida de forma diversa. Ambos consideram Ralph Tyler o pai da avaliação educativa.

O primeiro período, conhecido como pré-Tyler, começa no final do século XIX e se estende até o início do século XX. Caracteriza-se pela elaboração e aplicação de testes e práticas de mensuração. Aqui, avaliar confundia-se com medir.

No século $X X$, a avaliação começa a se desenvolver como prática aplicada à educação. Edward L. Thorndike foi muito importante no que se refere ao uso de testes com fins classificatórios, na elaboração de escalas e 
nas técnicas quantitativas, além de ser o precursor do movimento que mais tarde chamou-se gestão científica. A avaliação era técnica com seus testes de verificação, mensuração e quantificação de aprendizagem dos estudantes. Esta última foi o problema central da psicologia naquele momento, pois acreditava-se que pudesse haver um controle do processo por meio de métodos científicos de análise.

Tyler (1976) é considerado o maior expoente do segundo período, pois, como pai da avaliação educacional, focaliza os objetivos educacionais. A preocupação é a gestão que envolve o desenvolvimento curricular, e as instituições passam a determinar metas previamente formuladas. $\mathrm{O}$ autor as define em termos de comportamento dos estudantes, e estes devem ser capazes de diferenciar os objetivos previstos dos obtidos. A avaliação caracteriza-se como instrumento de regulação, pois define aonde quer chegar com clareza. Nessa época, também há a expansão da tecnologia de elaboração dos testes, movidos pela sensação de que os instrumentos técnicos são capazes de quantificar e classificar sem risco de erros. A característica principal deste segundo momento é a descrição de padrões e critérios relativos ao alcance dos objetivos previamente descritos. $\mathrm{O}$ importante é a relação entre o prometido e o cumprido.

Ainda neste segundo momento, a avaliação se desenvolve de acordo com o paradigma da racionalização científica que caracteriza a pedagogia por objetivos, e já apresenta a idéia de eficiência, conceito até então utilizado nas indústrias. Ela passa a ser o instrumento para diagnosticar a eficiência da escola e dos processos pedagógicos e administrativos.

O terceiro período (considerado a era da inocência) vai de 1946 a 1957. Caracteriza-se por certo descrédito da avaliação e da educação.

No quarto período, chamado de realismo, a avaliação torna-se mais complexa e sistêmica. Ela passa a ser formativa e o foco são as decisões a serem tomadas. O processo interno adquire importância e as decisões de mudança são tomadas durante o desenvolvimento do programa. Para Scriven (1967), a noção de decisão para a melhoria de cursos e programas é alvo de estudos e a distinção entre funções e objetivos, sendo que as funções se referem ao emprego das informações para tomadas de decisão. Tem-se então a clássica diferenciação entre avaliação formativa (que se realiza no decorrer do processo com intervenções imediatas) e a somativa (realizada somente ao final do processo).

O quinto período é denominado período do profissionalismo ou profissionalização da avaliação. É uma fase de construção teórica e proposta de novos modelos, e a avaliação ganha visibilidade. Stuffebeam e Shinkfield (1987) destacam as principais contribuições dessa época: 120 
incremento e melhora da comunicação, qualificação, preparação e titulação de avaliadores, cooperação entre organizações profissionais relacionadas à avaliação educacional, melhor comunicação entre partidários dos métodos positivistas quantitativos e fenomenológicos qualitativos. $\mathrm{O}$ paradigma positivista é questionado e o enfoque qualitativo é enfatizado. Nesse momento a avaliação é caracterizada como julgamento de valor, superando seu sentido descritivo e diagnóstico.

Já na gestão contemporânea a avaliação não pode se limitar a descrever, levantar informações, informar, mas passa a ter função ativa, procurando a melhoria do processo enquanto o mesmo se desenvolve, agindo em cada etapa e garantindo maior efetividade educacional.

Para Castanheira e outros (2005)

A avaliação de caráter educativo é uma prática social, voltada para obtenção de informações que gerem reflexões sobre a melhoria real da qualidade e da quantidade das atividades pedagógicas, científicas, administrativas e até sociais e profissionais. A avaliação não deve ser um processo de simples controle, pois deve haver sempre reais questionamentos e análises que facilitem o cumprimento dos compromissos institucionais. A avaliação é formativa, sem deixar de utilizar certos instrumentos e procedimentos de controle.

A avaliação deve ser, além de somativa sob certo aspecto, prioritariamente formativa, interferindo continuamente nos processos desenvolvidos; portanto, não é vista como um processo exterior; são os participantes que melhor conhecem os significados e ocupam funções ativas no conjunto de ações.

Para Sobrinho (2003)

$\mathrm{Na}$ avaliação educacional há uma mudança significativa de conceitos de aprendizagem que já não é entendida como mudança de comportamento, mas sim como construção de significado. O currículo passa a ser concebido em seu sentido mais amplo, os projetos pedagógicos ganham espaço e a avaliação busca dar conta das inúmeras facetas tendo que se utilizar de muitas metodologias. (p. 28)

Atualmente, a avaliação e suas práticas ocupam o centro das preocupações, tanto das instituições de ensino superior como do próprio Governo Federal que, por meio da Lei n. 10.861 de 14 de abril de 2004, institui o Sistema Nacional de Avaliação da Educação Superior (Sinaes). Essa lei, em seu art. 11, previu que cada instituição pública ou privada deveria constituir uma Comissão Própria de Avaliação, com atribuições de condução de processos avaliativos internos. Todas as instituições serão 
avaliadas levando em conta dez dimensões do Sinaes, sendo a segunda dimensão dedicada especialmente ao corpo de professores da instituição.

Alguns aspectos são muito relevantes e contribuirão de forma decisiva para a avaliação positiva das universidades:

- Avaliar a coerência da constituição e da formação do corpo docente com as funções essenciais da instituição.

- Avaliar as formas e a intensidade do envolvimento dos professores no cumprimento dos principais objetivos instituicionais.

- Identificar e avaliar as políticas de formação continuada dos professores, mencionando, quando for o caso, os incentivos claramente estabelecidos na carreira docente e as principais carências e dificuldades

- Avaliar a articulação entre professores das diferentes disciplinas, dos distintos cursos, centros ou áreas.

- Avaliar as políticas de capacitação contínua do corpo docente que estimulam as práticas de pesquisa e de reflexão individual e coletiva sobre a própria atividade.

\section{AS COMPETÊNCIAS PERTINENTES À DOCÊNCIA NA UNIVERSIDADE}

Levando em conta as orientações do Sinaes (Brasil, 2004), quanto às competências docentes, tem-se algumas considerações. Atualmente, as estratégias em sala de aula estão relacionadas a uma situação de ensino da qual necessariamente decorre a aprendizagem. $\mathrm{O}$ professor passa a ser o moderador das atividades, orientando, provocando, refletindo, e não somente expondo suas idéias.

A questão necessária à identificação das competências pertinentes à docência no ensino superior é apresentada a seguir: como formar seres humanos integralmente sem manifestar nas relações intra e interpessoais o respeito mútuo, a coerência, a ética, a humildade, a autenticidade e a solidaridedade, entre outros atributos necessários na relação com o outro?

Nesse contexto, como possibilidade de encaminhamento para a formação de professores para o ensino superior - mediadores no processo de ensinagem -, evidencia-se que a universidade e o meio acadêmico não podem se furtar ao chamamento que lhes é imposto e às graves responsabilidades de que são depositários como fórum competente, que se constituem para o debate, a reflexão, a exposição de idéias e a consolidação de ideais, com base em uma educação compreensiva e significativa, apresentando-se para tal finalidade uma conduta interdisciplinar, tendo por objetivo a construção coletiva desses programas de formação e suas práticas avaliativas. 
Libâneo e outros (2003) enfatizam que a formação docente, tanto inicial como continuada, precisa incluir em seus estudos as ações de desenvolvimento organizacional, o desenvolvimento de competências individuais e grupais, visando a participação de modo ativo e eficaz da organização e da gestão no âmbito educacional. Assim, o trabalho na universidade está relacionado aos processos de mudança nas formas de gestão e avaliação, e mudanças nos modos individuais de perceber, pensar e agir a serviço da organização escolar, o que requer conhecimentos, habilidades, atitudes e procedimentos práticos para melhor atender a aprendizagem dos estudantes.

Os autores elencam ações concretas que devem ser desenvolvidas com o intuito de assegurar um clima de trabalho adequado, eficiente e eficaz, em que objetivos e processos de decisão compartilhados existem de fato, permitindo canalizar o envolvimento e as atividades das pessoas para realizarem as tarefas e obterem resultados, colaborando para o funcionamento adequado por meio de avaliações em diferentes contextos.

Libâneo e outros (2003) indicam como necessárias as seguintes ações:

Formação de uma boa equipe de trabalho; construção de uma comunidade democrática de aprendizagem; promoção de ações de desenvolvimento profissional; envolvimento dos alunos em processos de solução de problemas e de tomada de decisões; fortalecimento de formas de comunicação e de difusão de informações, entre outros. O que exige pesquisar formas avaliatórias que contemplem conjuntamente aspectos do processo e dos resultados. (p. 295)

Convida-se, assim, para um fórum permanente de debates que se confirma por meio de projetos interdisciplinares, apresentando nas atividades desenvolvidas, eficiência, eficácia e efetividade na busca pela qualidade do ensino, da pesquisa e nos relevantes serviços prestados à comunidade, relativos às questões acadêmicas e sociais.

Para Monezi (2004), a otimização no processo de formação do educador implica conquistar a autonomia para a construção do próprio caminho na nova trajetória transformacional, o que exige atitudes próativas, organizadas, éticas, positivas, flexíveis, bem como iniciativas educacionais que valorizem a diversidade, e, ainda, participação efetiva nos relacionamentos interpessoais.

Anastasiou e Alves (2003), com base em suas pesquisas, indicam quatro competências que o professor deve ter: competência pessoal (aprender a ser); competência relacional (aprender a conviver); competência produtiva (aprender a fazer); competência cognitiva (aprender a conhecer), que 
correspondem aos quatro pilares da Educação, apontados por Delors (1998).

Para Masetto (2003), a docência na universidade exige competências próprias que, por uma questão de profissionalismo, precisam ser refletidas na Didática do Ensino Superior.

\section{A FORMAÇÃO CONTINUADA DE DOCENTES PARA O ENSINO SUPERIOR NA UNIVERSIDADE PRESBITERIANA MACKENZIE}

Para ilustração das considerações abordadas anteriormente e atendendo as orientações do Sinaes (Brasil, 2004), foi oferecido o Curso de Capacitação Didática do Ensino Superior aos professores do Centro de Comunicação e Letras/Mackenzie (CCL), em março de 2007, pelo Fórum Permanente de Educação, Pesquisa e Extensão (FOPEP) vinculado ao Centro de Ciências e Humanidades $(\mathrm{CCH})$. Observa-se que o FOPEP veio suprir a necessidade de constituir um corpo docente que desenvolvesse abordagens adequadas em diferentes temáticas.

Este grupo, formado em sua maioria por professores do $\mathrm{CCH}$, tem realizado reuniões com a finalidade de refletir sobre a função social da universidade, em razão das exigências da sociedade contemporânea; a identidade e os desafios da profissão docente, bem como a articulação e inter-relação da teoria educacional e da prática pedagógica no ensino superior. Eles têm manifestado em suas atividades a indissociabilidade entre ensino, pesquisa e extensão, tendo em vista o seu envolvimento em estudos, na docência e nas atividades de extensão da universidade com base em componentes curriculares e atenção às questões comunitárias e aos problemas sociais, detectados pela pesquisa e focalizados na extensão.

Os participantes deste curso demonstraram interesse nas questões relacionadas à docência do ensino superior: aceitam o desafio de rever os seus paradigmas pessoais e profissionais em uma proposta educacional integradora, voltada ao conjunto de conhecimentos, habilidades e atitudes necessários à formação integral de profissionais de sua área de trabalho. Foram apresentadas as seguintes temáticas: 1) Profissão Professor; 2) Habilidades Didáticas do Professor Competente; 3) Dimensões do Processo Ensino-Aprendizagem: Relação Professor-Aluno; 4) Ação Pedagógica Orientação para Elaboração de Plano de Ensino; 5) Avaliação Institucional e de Aprendizagem; 6) A origem do Mackenzie (histórico da instituição e sua missão); 7) Estratégias de Ensino e Aprendizagem; 8) Projetos Interdisciplinares no Ensino Superior; 9) Elaboração do Plano de Ensino com Planejamento de Aulas; 
10) Socialização dos Planos de Ensino. Fechamento das atividades desenvolvidas: avaliação conjunta dos encontros.

\section{AVALIAÇÃO DAS TEMÁTICAS PROPOSTAS}

Ressaltando mais uma vez as políticas que estimulam as práticas de reflexão individual sobre a própria atividade, algumas questões foram levantadas no sentido de discutir a respeito do curso e sua contribuição na formação continuada dos docentes do CCL. Destaca-se, nesta reflexão, o instrumento de avaliação de caráter formativo com as respectivas respostas dos participantes e seus comentários:

\subsection{Avaliação do curso: nível de satisfação}

Atribuiu-se valores de 1 a 5 , sendo 1 muito ruim e 5 muito bom. Após a tabulação obteve-se os seguintes resultados:

Tabela 1 - Médias obtidas sobre as Temáticas Desenvolvidas

\begin{tabular}{|l|c|c|}
\hline \multicolumn{1}{|c|}{ Temáticas } & $\begin{array}{c}\text { Interesse do } \\
\text { conteúdo } \\
\text { desenvolvido }\end{array}$ & $\begin{array}{c}\text { Tempo da } \\
\text { atividade }\end{array}$ \\
\hline Ensino Superior - Profissão Professor & 4,29 & 3,88 \\
\hline $\begin{array}{l}\text { Habilidades Didáticas do Professor } \\
\text { Competente }\end{array}$ & 4,37 & 4,00 \\
\hline $\begin{array}{l}\text { Dimensões do Processo Ensino-aprendizagem } \\
\text { Relação Professor-aluno }\end{array}$ & 4,28 & 3,78 \\
\hline $\begin{array}{l}\text { Ação Pedagógica - Orientação para } \\
\text { Elaboração de Plano de Ensino }\end{array}$ & 4,72 & 4,36 \\
\hline Avaliação Institucional e de Aprendizagem & 4,71 & 4,61 \\
\hline A origem do Mackenzie & 4,21 & 4,00 \\
\hline Estratégias de Ensino e Aprendizagem & 4,92 & 4,69 \\
\hline Projetos Interdisciplinares no Ensino Superior & 4,70 & 4,47 \\
\hline $\begin{array}{l}\text { Elaboração do Plano de Ensino com } \\
\text { Planejamento de Aulas }\end{array}$ & 4,92 & 4,46 \\
\hline Socialização dos Planos de Ensino & 4,88 & 4,72 \\
\hline
\end{tabular}

Os professores que orientaram os trabalhos também foram avaliados pelos alunos-docentes. A média de satisfação foi de 4,8, 
demonstrando, assim, a importância do evento e quanto todos estavam motivados.

Para uma participação de caráter mais qualitativo, foram propostas questões abertas, abrindo espaço para sugestões e opiniões de forma efetiva.

\subsection{Questões abertas}

1) Você acha que o convívio propiciado por este curso contribuirá positivamente para a melhoria das condições do trabalho e da docência na sua Unidade (CCL)? Justifique sua opinião, se possível, citando as atividades mais proveitosas e as que não trouxeram contribuição.

Respostas das questões depois de categorizadas:

Sim, contribuirá pelos motivos elencados abaixo:

Conhecer a instituição e os colegas de trabalho.

Conhecer mais estratégias para utilizar em sala de aula.

Estratégias de ensino e aprendizagem.

Projetos interdisciplinares.

Relação Professor-Aluno.

Solução dos planos de ensino e das experiências individuais de cada um.

Troca de experiência.

Integração entre as disciplinas.

Compreensão do funcionamento da universidade.

Gerando abertura de discussões.

Aconchego aos novatos e socialização.

Aprender a mudar o foco do plano de ensino.

Sem dúvida! O curso vale para os mais novos como para os mais antigos professores da Unidade. Creio que todas as atividades são proveitosas e, em menor ou maior grau, contribuem para o trabalho do professor.

A origem do Mackenzie deveria estar no "plano de integração" para todos os professores somado ao planejamento estratégico que precisa ser comunicado. O aprendizado foi excelente e deveria continuar.

Este curso é fundamental para integração e atualização do profissional inserido no curso. O convívio foi muito bom, considerando que os professores não tinham se visto antes, na sua maioria. 
Sim, o convívio propiciado pela troca de experiências entre as diversas disciplinas e seus métodos de aprendizagem foi um dos pontos altos deste curso, além da experiência relatada pelos professores que aqui estiveram dando o curso.

O convívio propiciou a troca de experiência, valores e aproximou profissionais, gerando um caminho mais humano a ser seguido, aplicado em sala de aula. Dividindo as angústias, aprendemos com elas.

Sim, acho. As mais proveitosas foram as diversas técnicas de ensino/aprendizagem e a discussão/reflexão sobre os planos de ensino.

Os encontros permitiam a integração do novo professor junto aos demais professores da casa, inclusive de cursos diferentes, provocando já uma interdisciplinaridade; na minha opinião todas as atividades foram proveitosas e contribuíram para a formação do "eu-professor".

2) Você acha que novos encontros como estes devem ser realizados no futuro? Se sua resposta é SIM, você tem sugestões para melhorar o rendimento dos encontros?

Se a sua resposta é NÃO, você tem alguma sugestão de iniciativas que poderiam substituir este encontro?

Todos responderam sim com as seguintes sugestões:

Sempre! Apenas devemos mudar o período. Talvez realizarmos durante o recesso. Sugiro que o curso seja feito dentro do processo de "integração" do professor no Mackenzie, em parceria com o RH.

Espaços para leitura e aproveitamento dos exercícios em conjunto e participação dos professores veteranos é fundamental para o enriquecimento do resultado individual.

O curso deveria ser mais rápido.

Disponibilidade de outros horários (durante a semana, por exemplo) e criação de fóruns de discussão na internet.

Esse tipo de iniciativa deveria ser freqüente, especialmente para contribuir para a aproximação da equipe. 
Atividades mais práticas, até de contato para ouvir alunos e/ou recémformados. Enfim, ouvir "o outro lado". Outra coisa, não ser feito o sábado todo, mas sim dividido.

Esses encontros precisam acontecer constantemente e a sugestão é tematizar os encontros, com ênfase na formação do docente.

Acredito que deva se transformar em um projeto, apresentado regularmente (todo semestre), com pouco mais de prática.

Participação de mais professores (antigos). Uma melhor visualização dos erros e acertos, favorecendo as mudanças em conjunto.

Acredito que poderiam ser feitas atividades diretamente ligadas ao curso, ou seja, dedicar mais tempo à elaboração dos planos, à leitura dos testes propostos, etc.

Acredito que estes cursos são sempre bem-vindos e poderiam acrescentar muito à nossa formação. Quanto a sugestões, poderiam acrescentar algumas matérias que tenham afinidades com os vários profissionais que participam dos cursos.

O curso poderia ser oferecido no último ou primeiro sábado do mês, em cronograma pré-definido, e apenas 4 horas à tarde.

Talvez uma divulgação maior sobre o curso, para que haja mais interação entre os colegas.

Estes encontros precisam ser propostos sempre, talvez no início de cada semestre, com encontros gerais e principalmente em relação às disciplinas (professores da mesma área).

A sugestão é um horário mais compactado. Exemplo: das 10h às 13he das $14 \mathrm{~h}$ às $17 \mathrm{~h}$. 1 hora de almoço é suficiente. Falando nisso, o almoço deve ser estratégico também para a manutenção do grupo. Seria interessante ter sugestão de um lugar para que todos possam ir. Por último, um curso como este pede sempre um coffee-break, tanto pela manhã quanto à tarde. Todos sentiram falta disto.

Sugiro algo mais específico sobre interdisciplinaridade e que haja encontros com outros temas específicos. 
Os participantes perceberam a importância e a necessidade de se pensar sistematicamente a docência do ensino superior, dada a relevância das temáticas apresentadas. As mais significativas foram: Elaboração do Plano de Ensino com Planejamento de Aulas, Estratégias de Ensino e Aprendizagem, Socialização dos Planos de Ensino e Ação Pedagógica - Orientação para Elaboração de Plano de Ensino.

Os professores deixaram clara a preocupação em dividir as angústias com seus pares, e acreditam que discutir os projetos do curso, se envolver em atividades extraclasse e trocar experiências vai tornar sua prática diária mais agradável e eficaz.

Configuram-se, assim, os compromissos pertinentes ao projeto político-pedagógico diferenciado, ao estabelecer a articulação entre a teoria educacional e a prática pedagógica; as intenções educativas decididas coletivamente, com documento norteador de cada curso da universidade; e o processo de construção e aperfeiçoamento contínuos.

\section{CONSIDERAÇÕES FINAIS}

A auto-avaliação institucional deve ter caráter educativo, de melhoria constante e de auto-regulação. Quanto mais ampla e dedicada a participação dos envolvidos mais resultados positivos surgirão e maior será a eficiência dos processos pedagógicos desenvolvidos. Para Monezi (2003), como efeito dessa iniciativa promovida pela universidade quanto ao incentivo ao desenvolvimento profissional, manifestam-se os compromissos científicos (princípios, fatos, conceitos) e filosóficos (valores, atitudes e normas) do professor para a resolução de conflitos, e indicação de caminhos para que um método dialético de construção do conhecimento seja evidenciado para o enfrentamento dos desafios educacionais e comunitários.

O professor é, sem dúvida, o ator principal do processo de ensinoaprendizagem, e a motivação torna-se essencial para que as metas e objetivos educacionais sejam atingidos. Ele deve participar sempre, se envolver com os cursos oferecidos, avaliando cada passo, contribuindo com suas idéias e concepções, e tendo acesso a toda informação possível sobre a instituição na qual leciona.

Analisando-se os resultados da avaliação do curso de Didática oferecido, percebe-se claramente a falta de iniciativas para elucidar alguns pontos nebulosos e para discutir projetos pedagógicos e planos de ensino.

Após refletir sobre aspectos tão significativos da educação profissional para a docência na universidade, pode-se inferir que nos dias 
de hoje a universidade perdeu suas fronteiras espaciais e temporais, destacando-se o compromisso de todos com o social, o cultural e o comunitário. A universidade tem o papel de proporcionar condições para que os educadores/professores sintam-se envolvidos como sujeitos éticos do processo, que, entusiasmados, tenham vontade de sonhar, e que, comprometidos, percebam a articulação e a indissociabilidade do ensinopesquisa-extensão, com oportunidades para criar, fazer acontecer.

\section{REFERÊNCIAS BIBLIOGRÁFICAS}

ANASTASIOU, L. G. C.; ALVES, L. P. (orgs.). Processos de ensinagem na universidade: pressupostos para as estratégias de trabalho em aula. Joinville, 2003. Tese (dout.) UNIVILLE.

BALZAN, N. C. Indissociabilidade ensino-pesquisa como princípio metodológico. In: VEIGA, I. P. A.; CASTANHO, M. E. L. M. (orgs.). Pedagogia universitária: a aula em foco. Campinas: Papirus, 2000, p.115-136.

BRASIL. Ministério da Educação. Sistema Nacional de Avaliação da Educação Superior - Sinaes: da concepção à regulação. Brasília: Inep/ MEC, 2004.

CASTANHEIRA, A. M. P et al. Avaliação e formação de docentes sob a ótica do Sinaes. In: CONGRESSO BRASILEIRO DE ENSINO DE ENGENHARIA, 33. Anais do... Campina Grande: UFCG, 2005. CD-ROM.

CASTANHO, S.; CASTANHO, M. E. (orgs.). Temas e textos em metodologia do ensino superior. 2.ed. Campinas: Papirus, 2002.

DELORS, J. Educação: um tesouro a descobrir. Brasília: MEC; Unesco, 1998.

LIBÂNEO, J. C. et al. Educação escolar: políticas, estrutura e organização. São Paulo: Cortez, 2003.

LOWMAN, Joseph. Dominando as técnicas de ensino. São Paulo: Atlas, 2004.

MASETTO, Marcos T. Competência pedagógica do professor universitário. São Paulo: Summus, 2003.

Professor universitário: um profissional da educação na atividade docente. In: . (org.). Docência na universidade. São Paulo: Papirus, 1998, p. 9-26. 
MONEZI, M. R. C. Atitude interdisciplinar na docência. Revista de Cultura: revista do IMAE. São Paulo: IMAE, v. 4, n. 9, p. 56-60, jan./jun. 2003.

- Desafios contemporâneos para a formação do educador. Educare: revista da Faculdade de Pedagogia do UniFMU. São Paulo: Centro UniFMU, v.1, n.1, p. 23-29, jan./dez. 2004.

MONEZI, M. R. C.; RIBEIRO, M. C. C. M.; LAGUNA, A. J. Paradigmas contemporâneos da gestão educacional: uma visão inclusiva. Revista de Cultura: revista do IMAE. São Paulo: IMAE, v. 5, n. 11, p. 54-62, jan./jun. 2004.

PIMENTA, S. G.; ANASTASIOU, L. G. C. (orgs.). Docência no ensino superior. São Paulo: Cortez, 2002.

SCRIVEN, M. The Methodology of evaluation. In: STAKE, R. E. (ed.) Curriculum Evaluation. Chicago: Rand-McNally, 1967. (American Educational Research Association: monograph series on curriculum evaluation, n. 1).

SOBRINHO, J. D. Avaliação: políticas educacionais e reformas da educação superior. São Paulo: Cortez, 2003.

STUFFEBEAM, D. L.; SHINKFIELD, A. J. Evaluación sistemática: guia teórica y práctica. Madri: Paidós, 1987.

TYLER, R. W. Princípios básicos de currículos e ensino. Porto Alegre: Globo, 1976.

VANNUCCHI, A. A Universidade comunitária. São Paulo: Loyola, 2004.

VEIGA, I. P. A. Projeto político-pedagógico: continuidade ou transgressão para acertar? In: CASTANHO, S.; CASTANHO, M. E. (orgs.). O que há de novo na educação superior: do projeto pedagógico à prática transformadora. Campinas: Papirus, 2000, p. 183-219.

Recebido em: junho 2007

Aprovado para publicação em: outubro 2007 
